\title{
Role of SLC39A6 in the development and progression of liver cancer
}

\author{
$\mathrm{ZHEN} \mathrm{WAN}^{1 *}$ and XUZHEN WANG ${ }^{2 *}$ \\ Departments of ${ }^{1}$ General Surgery and ${ }^{2}$ Critical Care Medicine, \\ The First Affiliated Hospital of Nanchang University, Nanchang, Jiangxi 330006, P.R. China
}

Received July 29, 2021; Accepted December 21, 2021

DOI: $10.3892 / \mathrm{ol} .2022 .13197$

\begin{abstract}
Liver cancer is one of the most common malignant solid tumor types worldwide. The solute carrier (SLC)39A family is a main member of the SLC group of membrane transport proteins, which transfer zinc to the cytoplasm when cells are depleted of zinc; thus, it may provide a novel therapeutic target for human cancer. However, the prognostic value of SLC39A genes in patients with liver cancer has remained elusive. Therefore, the present study aimed to explore whether SLC39A family genes are associated with the survival rate of patients with liver cancer and to investigate the role of key genes of the SLC39A family in liver cancer. The mRNA expression of the SLC39A family in liver cancer was obtained from the UALCAN database. Survival curve analysis was performed to investigate the prognostic value of SLC39A family genes in the overall survival of patients with liver cancer. In addition to the bioinformatics analysis, SLC39A6 was knocked down in HepG2 and Hep3B cells to examine the effect on the proliferation, migration and invasion of liver cancer cells. The results suggested that SLC39A6 was significantly upregulated in liver cancer tissues compared with normal liver tissues. High expression of SLC39A6 was significantly associated with poor overall survival of patients with liver cancer. Furthermore, knockdown of SLC39A6 inhibited the proliferation, migration and invasion of liver cancer cells in vitro and in vivo. Collectively, the results of the present study suggested that SLC39A6 may be a promising prognostic biomarker for liver cancer and is associated with the proliferation, migration and invasion of liver cancer.
\end{abstract}

Correspondence to: Professor Zhen Wan, Department of General Surgery, The First Affiliated Hospital of Nanchang University, 17 Yongwai Road, Nanchang, Jiangxi 330006, P.R China

E-mail:whliuh@126.com

*Contributed equally

Key words: liver cancer, solute carrier 39A family, solute carrier 39A6, progression, prognostic biomarker

\section{Introduction}

Liver cancer is the fourth leading cause of cancer-related mortality and is ranked sixth in terms of cancer incidence; it is estimated that over one million individuals will succumb to the disease by 2030 (1). In the US, the 5-year survival rate for patients with liver cancer is $18.1 \%$ (2), while in China, it is only $12.1 \%$ (3). The majority of primary liver cancers are pathologically diagnosed as hepatocellular carcinoma, accounting for $70-85 \%$ of cases (4). Previous studies have reported that the majority of liver cancers occur in patients with chronic liver diseases, including hepatitis $\mathrm{B}$ virus or hepatitis $\mathrm{C}$ virus infection (5), non-alcoholic fatty liver disease (6) and alcohol abuse (7). To date, surgical excision, radiofrequency ablation, interventional embolization, liver transplantation, as well as targeted and systemic therapies have been applied in the treatment of liver cancer, which have improved the prognosis of those patients to a certain extent (8). Thus, further elucidation of the molecular mechanisms involved in the occurrence and development of liver cancer is warranted, as this may contribute to the development of novel preventive, diagnostic and therapeutic strategies for liver cancer.

Previous studies have indicated that zinc, an important nutrient (9), has a key role in organisms, including growth, development, reproduction, enzyme function, immune function, DNA repair, gene expression and endocrine function, as well as cancer biology (9-12). Under normal conditions, 98\% of zinc is localized in the intracellular compartment (11). The balance of intracellular and extracellular zinc is regulated by the Zrt- and Irt-like proteins [ZIP/solute carrier (SLC)39 family, SLC39A] and the SLC30 family (SLC30A/ZnT) $(13,14)$. The $\mathrm{ZnT}$ family member functions to move zinc from the inside of the cell to the outside (13), while the ZIP family member (SLC39A1-14) serves to pass zinc into the cytoplasm (14). An imbalance of zinc homeostasis may be associated with the development of a number of diseases. It has been demonstrated that zinc levels in prostate cancer cells are significantly reduced and are associated with metabolic reprogramming (15). However, increased zinc levels may also be associated with tumorigenesis and progression; for instance, SLC39A8 expression has been determined to be upregulated in early renal clear cell carcinoma (16), and SLC39A7 has been reported to have a key role in the growth and survival of breast cancer cells (17). To the best of our knowledge, the role of the SLC39A family 
in liver cancer has remained elusive. The present study performed an integrated bioinformatics analysis of several independent studies to explore the role of the SLC39A family in the development and progression of liver cancer. In addition, the function of SLC39A6, a key gene of the SLC39A family, in liver cancer was also investigated.

\section{Materials and methods}

UALCAN database. UALCAN is a public web portal that provides comprehensive tumor transcriptome data from The Cancer Genome Atlas (TCGA) (http://ualcan.path.uab.edu/). The relative mRNA expression of SLC39A in liver cancer and corresponding normal tissues was detected using the UALCAN database.

Gene expression profiling interactive analysis (GEPIA) database. The mRNA expression data of SLC39A family genes in liver cancer tissues, as well as the clinicopathological and survival data of patients with liver cancer were downloaded from the University of California Santa Cruz (UCSC) Xena browser (https://xenabrowser.net/). To determine the potential prognostic values of SLC39A family genes in patients with liver cancer, the association between SLC39A mRNA expression and the overall survival (OS) of patients with liver cancer was analyzed using the GEPIA database (http://gepia.cancer-pku. cn/) or by GraphPad Prism 6.0 (GraphPad Software, Inc.). The association of SLC39A family genes with disease-free survival (DFS) was also analyzed. Furthermore, the prognostic value of SLC39A6 mRNA expression in patients with different disease grades of liver cancer was also analyzed.

Oncomine database. Oncomine is a cancer microarray database to facilitate discovery from genome-wide expression analysis data (https://www.oncomine.org/resource/main. $\mathrm{html}$ ). The relative expression of SLC39A6 in the Mas (18), Chen (19) and Roessler (20) liver cancer and normal samples were downloaded from the Oncomine database.

Gene set enrichment analysis (GSEA). To identify the hallmark effect gene sets associated with SLC39A6 mRNA expression in the TCGA-Liver Hepatocellular Carcinoma dataset, GSEA was performed using GSEA software (v. 4.1.0; http://www. gsea-msigdb.org/gsea/login.jsp). For enriched genomes, pathways with false discovery rate values $<0.25$ and $\mathrm{P}<0.05$ were considered after 1,000 permutations as significantly enriched pathways.

Tissue samples. The study population included 12 patients who had been diagnosed with liver cancer (T3/T4) composed of 6 males and 6 females with a median age of 63.93 years (range, 56-78 years) between March 2021 and June 2021 at the Department of General Surgery, The First Affiliated Hospital of Nanchang University (Nanchang, China). Patients or their families who refused to provide liver cancer specimens were excluded. The present study was approved by the Human Research Ethics Committee of Nanchang University (no. 2021-027) and all the patients were fully informed of the study procedures orally and signed an informed consent form. The tumor tissues and normal tissues $(\sim 5 \mathrm{~cm}$ away from tumor tissue) were collected and then either immediately frozen in liquid nitrogen or fixed in formalin after the surgery.

Histological analysis. Three pairs of tumors and healthy tissue samples were fixed in $4 \%$ paraformaldehyde and embedded in paraffin. The sections were immunohistochemically (IHC) stained with SLC39A6 rabbit polyclonal antibody (cat. no. 14236-1-AP; 1:200 dilution; Proteintech Group, Inc.) and observed using microscopy (IX71; Olympus Corporation). IHC scores (21) were used to evaluate the expression level of SLC39A6. SLC39A6 staining intensity was scored as $0-3$ points $(0$, negative; 1 , weak; 2 , mild; 3 , strong). The percentage score of SLC39A6-positive cells was as follows: 0 , unstained; $1,1-25 ; 2,26-50 ; 3,51-75 ; 4,76-100 \%$ stained cells. The staining intensity score was then multiplied with the positive cell proportion score to obtain the final score.

Cells and cell culture. The human HepG2 and Hep3B liver cancer cell lines were obtained from Procell Life Science \& Technology Co., Ltd., and cultured in high-glucose DMEM (cat. no. SH30022.01) containing 10\% FBS (cat. no. SH30084.03) and 1\% penicillin-streptomycin (cat. no. SV30010; all from HyClone; Cytiva) in an incubator with $5 \% \mathrm{CO}_{2}$ at $37^{\circ} \mathrm{C}$. The authenticity of the cell lines was confirmed using short tandem repeat methods.

Cell transfection. The human SLC39A6 small interfering (si) RNA expression vector (si-SLC39A6) and corresponding negative control siRNA (si-NC) were synthesized and provided by Vigene Biosciences, Inc. The HepG2 and Hep3B cells were transfected with si-SLC39A6 and si-NC using Lipofectamine $2000^{\circledR}$ according to the manufacturer's protocol. The cells were collected at $48 \mathrm{~h}$ following transfection for use in subsequent experiments. Short hairpin (sh)RNA for SLC39A6 (Shanghai Genechem Co., Ltd.) and the corresponding control vector (Shanghai Genechem Co., Ltd.) were transfected into the HepG2 cells at a multiplicity of infection of 20 using enhanced infection solution (Shanghai Genechem Co., Ltd.) according to the manufacturer's protocol. The plasmid backbone (GV493) for shRNA-containing plasmid was provided by Shanghai Genechem Co., Ltd. Protein lysates and total RNA were collected $96 \mathrm{~h}$ following transfection to verify the transfection efficiency and for use in subsequent animal experiments. The sequences were as follows: si-SLC39A6, 5'-UUCCAU UGCUGGUUCUUCAUGGCUA-3' and si-NC, 5'-CGCTTC CGCGGCCCGTTCAA-3'; shRNA for SLC39A6, 5'-UUC CAUUGCUGGUUCUUCAUGGCUA-3' and the respective NC-shRNA, 5'-CGCTTCCGCGGCCCGTTCAA-3'.

Reverse transcription-quantitative PCR (RT-qPCR). Total RNA was isolated from 12 pairs of tumor and normal tissue samples from patients with liver cancer and liver cancer cell lines (HepG2 and Hep3B) using TRIzol ${ }^{\circledR}$ reagent (Invitrogen; Thermo Fisher Scientific, Inc.) and reverse-transcribed into cDNA according to the manufacturer's protocol using an RT kit (Vazyme Biotech Co., Ltd.) at $95^{\circ} \mathrm{C}$ for $5 \mathrm{~min}$ and $65^{\circ} \mathrm{C}$ for $60 \mathrm{~min}$, and then kept at $4^{\circ} \mathrm{C}$ for storage. qPCR was performed using SYBR-Green qPCR Master Mix (Vazyme Biotech Co., Ltd.). The qPCR conditions were used as follows: Initial denaturation at $95^{\circ} \mathrm{C}$ for $5 \mathrm{~min}$, followed by 40 cycles of denaturation at $95^{\circ} \mathrm{C}$ for $30 \mathrm{sec}$, 
annealing at $52^{\circ} \mathrm{C}$ for $30 \mathrm{sec}$ and extension at $72^{\circ} \mathrm{C}$ for $30 \mathrm{sec}$ Each sample was repeated in triplicate in qPCR step. The relative mRNA levels were normalized to $\beta$-actin. The primer sequences were as follows: SLC39A6 forward, 5'-GCCGCGGAGACTGTT TCAAT-3' and reverse, 3'-TGTTGCATTCAGCGGAACCT-5'; and $\beta$-actin forward, 5'-GGCTCTTTTCCAGCCTTCCT-3' and reverse, 3'-AATGCCAGGGTACATGGTGG-5'. The relative gene expression level was analyzed by the $2^{-\Delta \Delta \mathrm{Cq}}$ method (22).

Western blot analysis. Proteins were extracted from tissues from patients with liver cancer and cell lines (HepG2 and Hep3B) using radioimmunoprecipitation assay buffer containing protease inhibitor. The protein concentration was determined using a bicinchoninic acid assay. For western blot analysis, $50 \mu \mathrm{g}$ of protein per lane was separated by $15 \%$ SDS-PAGE and transferred onto nitrocellulose membranes (cat. no. FFN08; Beyotime Institute of Biotechnology). The membranes were blocked with $5 \%$ non-fat milk for $1 \mathrm{~h}$ at room temperature and incubated with polyclonal primary antibodies [SLC39A6 rabbit polyclonal antibody (cat no. 14236-1-AP; 1:1,000 diluted; Proteintech Group, Inc.) and $\beta$-actin mouse monoclonal antibody (cat. no. 66009-1-Ig; 1:5,000 diluted; Proteintech Group, Inc.)] in Tris-buffered saline containing Tween-20 (TBST) buffer overnight at $4^{\circ} \mathrm{C}$. The membranes were washed with TBST solution three times and incubated with secondary antibody [HRP-conjugated Affinipure goat anti-rabbit $\operatorname{IgG}(\mathrm{H}+\mathrm{L})$; cat. no. SA00001-2; 1:5,000 diluted; Proteintech Group, Inc.] for $1 \mathrm{~h}$ at room temperature. The target protein was visualized using enhanced chemiluminescence reagent (cat. no. 21050; Thermo Fisher Scientific, Inc.).

Colony formation assay. The HepG2 and Hep3B cells transfected with si-SLC39A6 or si-NC were seeded in 6-well plates at a concentration of 1,000 cells per well in $3 \mathrm{ml}$ complete medium. Following incubation at $37^{\circ} \mathrm{C}$ for 9 days, the cell colonies were fixed with $4 \%$ paraformaldehyde for $15 \mathrm{~min}$, stained with $0.04 \%$ crystal violet for $20 \mathrm{~min}$ at room temperature and images were acquired.

Cell proliferation assay. Cell proliferation was assessed using the Cell Counting Kit-8 (CCK-8) assay (cat. no. HY-K030; MedChemExpress). HepG2 and Hep3B cells transfected with si-SLC39A6 or si-NC were seeded in 96-well plates at a concentration of 1,000 cells per well in $100 \mu \mathrm{l}$ complete medium. After culturing the cells for 1-4 days, the medium was removed and $10 \mu \mathrm{l}$ CCK-8 stain was added per well. The absorbance at a wavelength of $450 \mathrm{~nm}$ was measured following incubation for $1 \mathrm{~h}$ using an automated microplate reader (Infinite F50; Tecan Group).

In vitro migration and invasion assays. In vitro migration and invasion assays were performed using 24-well Transwell chambers with $8-\mu \mathrm{m}$ pore size membranes. For the migration assay, the HepG2 and Hep3B cells transfected with si-SLC39A6 and si-NC were seeded in the upper chamber at a concentration of $2 \times 10^{4}$ cells per well in $200 \mu \mathrm{l} \mathrm{FBS-free} \mathrm{medium,} \mathrm{while} 500 \mu \mathrm{l}$ DMEM with $10 \% \mathrm{FBS}$ was added to the lower chamber. Following incubation at $37^{\circ} \mathrm{C}$ for $36 \mathrm{~h}$, the cells on the upper surface of the filters were removed and the cells that had migrated to the lower surface were fixed in $4 \%$ paraformaldehyde, subsequently stained with
$0.04 \%$ crystal violet for $20 \mathrm{~min}$ at room temperature and counted under a microscope (IX71; Olympus Corporation). For the invasion assay, the procedure was repeated as described above, but the membrane was initially coated with Matrigel ${ }^{\circledR}$ at $4^{\circ} \mathrm{C}$.

Animal experiment. A total of $2 \times 10^{6}$ HepG2 cells transfected with shRNA for SLC39A6 or the corresponding control vector were subcutaneously injected into the right infra-axillary dermis of 8 -week-old female nude mice $(n=5$ per group; the total number of the animals was 10 and the weight was $20.23 \pm 1.13 \mathrm{~g}$ ). All mice were provided by GemPharmatech Co., Ltd., and housed in a specific pathogen-free facility (temperature, $18-29^{\circ} \mathrm{C}$; relative humidity, 50-80\%). Tumor volumes were measured using a digital caliper every 3 days to access tumor growth and the tumor weight was measured when the mice were sacrificed on day 30 following cell implantation. The mice were anesthetized with $1 \%$ pentobarbital sodium at $50 \mathrm{mg} / \mathrm{kg}$ body weight by intraperitoneal injection and sacrificed by cervical dislocation. Tumor sizes were measured every 3 days, commencing at 6 days after the cells were implanted, for a total of nine times. According to previous authoritative studies (23-26), when the tumor volumes reached $2,000 \mathrm{~mm}^{3}$, the mice underwent euthanasia as the humane end-point of the study. The mean diameter did not exceed $1.5 \mathrm{~cm}$. In addition, if body weight loss exceeded $20 \%$, the animals became moribund or the subcutaneous tumor reached a volume of $2,000 \mathrm{~mm}^{3}$ or became necrotic, humane endpoints were considered to have been reached in the present study (25-28). All the animal experiments were performed in accordance with the guidelines provided by the UK Animals (Scientific Procedures) Act, 1986, the EU Directive 2010/63/EU and approved by the Ethics Committee for Animal Experiments of Nanchang Royo Biotech Co. Ltd., (no. RYE2021041402).

Statistical analysis. Statistical analysis was performed using SPSS 21.0 software (IBM Corp.) and GraphPad Prism 6.0 (GraphPad Software, Inc.). Values are expressed as the mean \pm standard deviation. All comparisons between the two groups were performed using unpaired Student's t-tests. For the two paired-group comparisons, the paired Student's t-test was used. The survival curves were compared by the log-rank test, while two-stage log-rank analysis (29) was used for those survival plots where late-stage crossover between the groups was present. Based on literature reports (29), P1 represents the $\mathrm{P}$-value prior to curve crossing, $\mathrm{P} 2$ represents the $\mathrm{P}$-value after curve crossing and $\mathrm{P}$ represents the $\mathrm{P}$-value for the whole. Univariate and multivariate analyses of OS and DFS according to prognostic factors were analyzed using Cox regression analysis. A value of $\mathrm{P}<0.05$ was considered to indicate a statistically significant difference.

\section{Results}

Relative mRNA expression of SLC39A family genes in liver cancer. To examine the expression levels of SLC39A family genes in liver cancer, the expression data of 14 SLC39A genes in patients with liver cancer from the TCGA database were analyzed using the UALCAN database. As presented in Fig. 1A-N, the expression of SLC39A1, SLC39A3, 
A

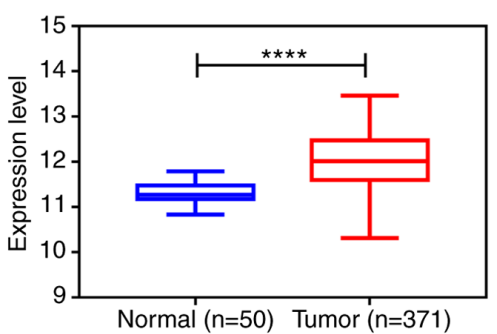

D

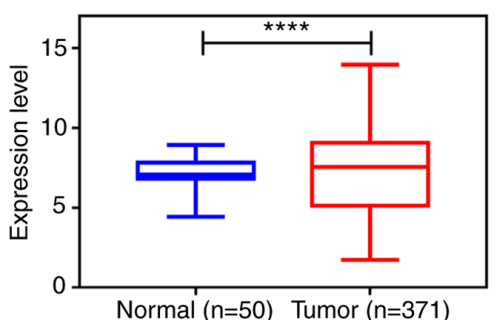

G

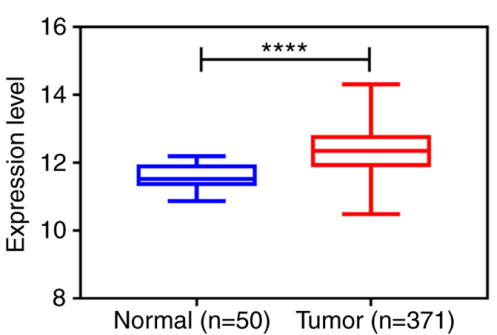

$J$

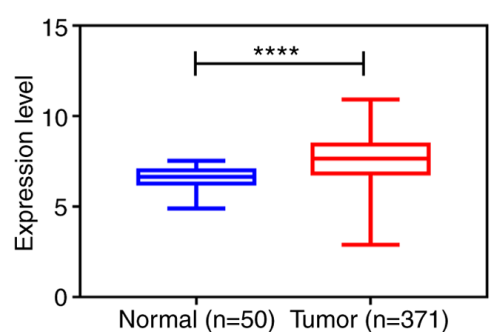

M

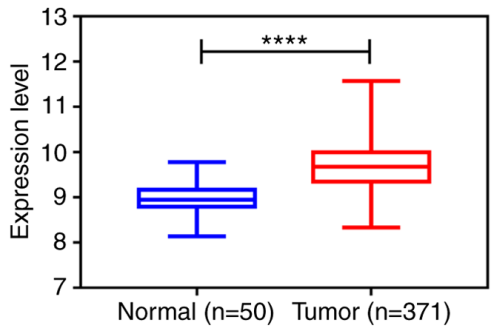

B

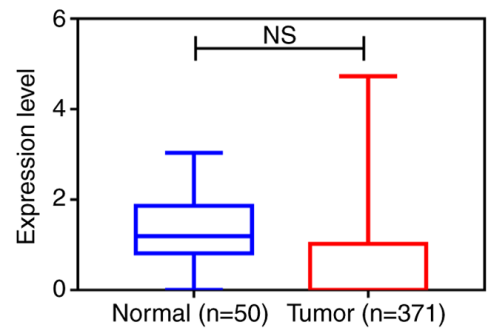

E

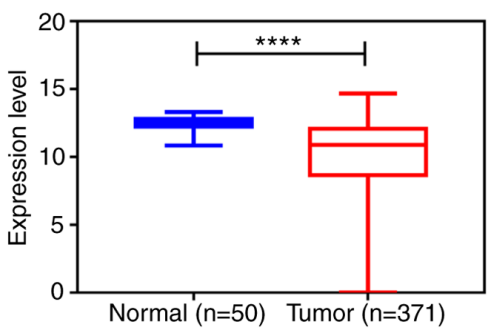

$\mathrm{H}$

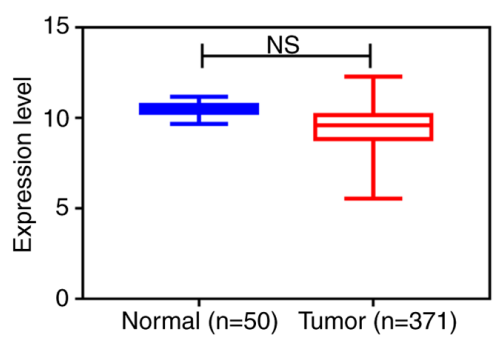

$\mathrm{K}$

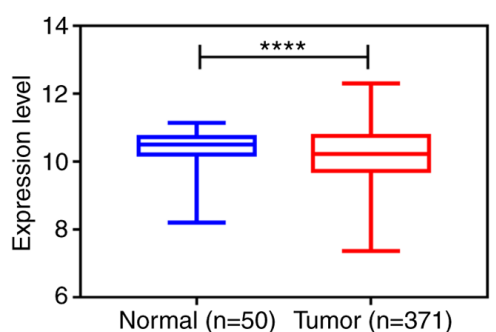

N SLC39A 14

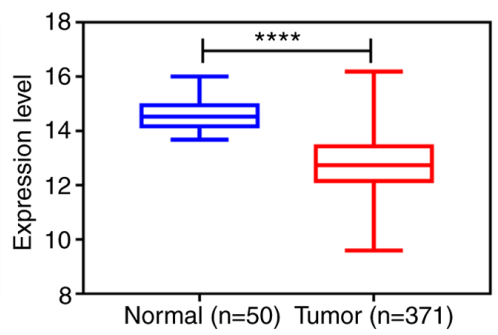

C

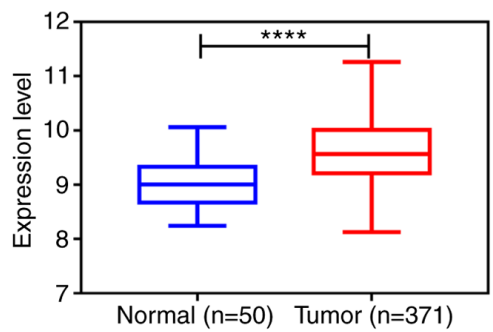

$\mathrm{F}$
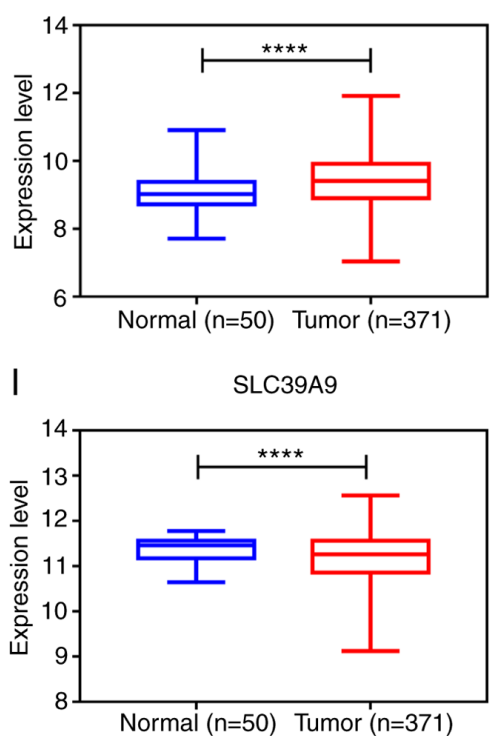

$\mathrm{L}$

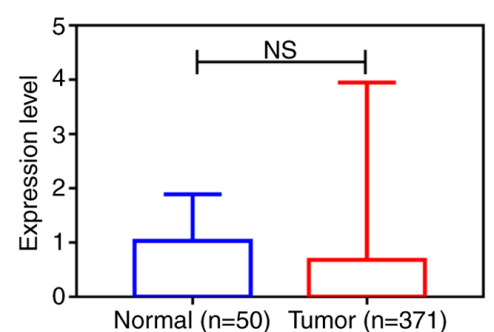

Figure 1. mRNA expression of SLC39A family genes in primary tumor and corresponding normal tissues in patients with liver cancer using the dataset from the UALCAN database. (A) SLC39A1, (B) SLC39A2, (C) SLC39A3, (D) SLC39A4, (E) SLC39A5, (F) SLC39A6, (G) SLC39A7, (H) SLC39A8, (I) SLC39A9, (J) SLC39A10, (K) SLC39A11, (L) SLC39A12, (M) SLC39A13 and (N) SLC39A14. ${ }^{* * * * *} \mathrm{P}<0.0001$. SLC, solute carrier; NS, no significance.

SLC39A4, SLC39A6, SLC39A7, SLC39A10 and SLC39A13 in the cancer tissues was significantly higher than that in healthy tissues; however, SLC39A5, SLC39A9, SLC39A11 and SLC39A14 were expressed at markedly lower levels in the tumor tissues compared with the normal tissues. The expression of SLC39A2, SLC39A8 and SLC39A12 exhibited no significant difference between cancer and normal tissues.

SLC39A genes have a high prognostic value in patients with liver cancer in the GEPIA dataset. The potential prognostic values of SLC39A family genes in liver cancer were investigated 
A

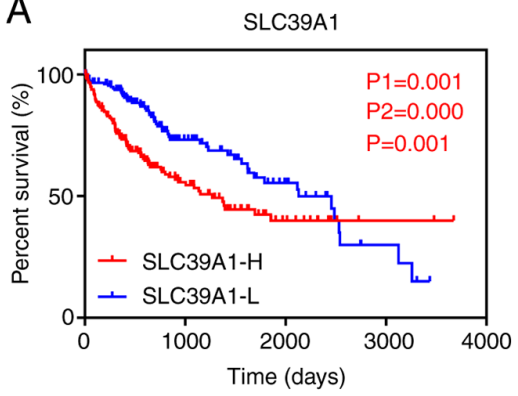

D

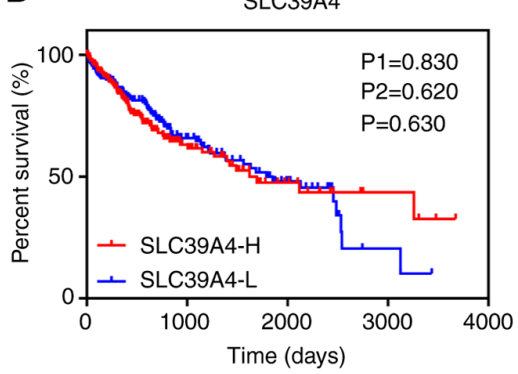

G

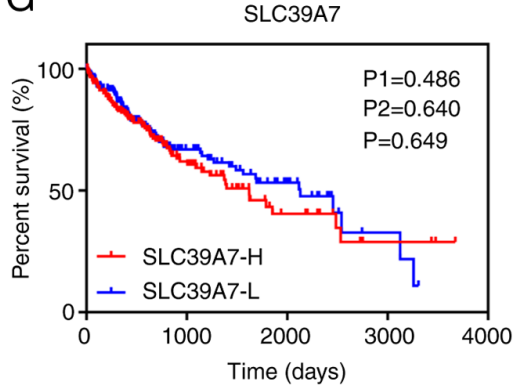

J

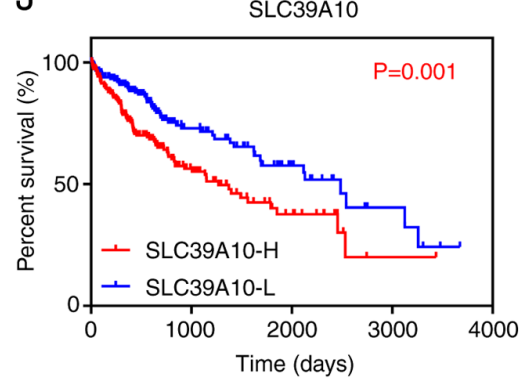

M

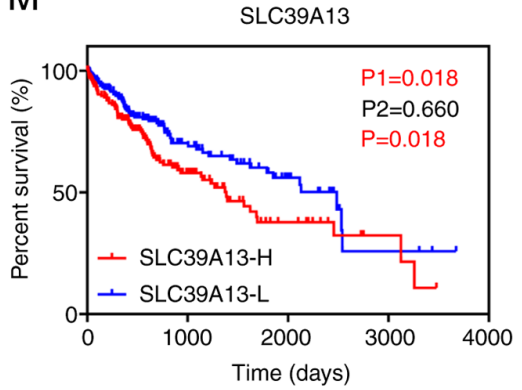

B

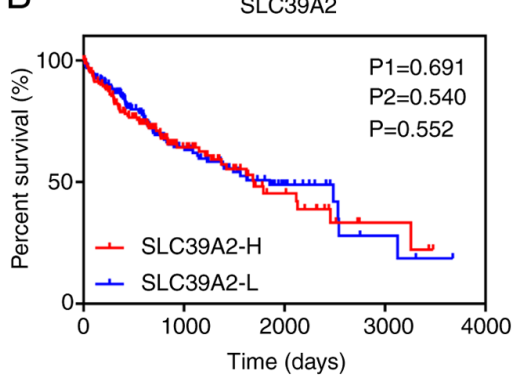

E

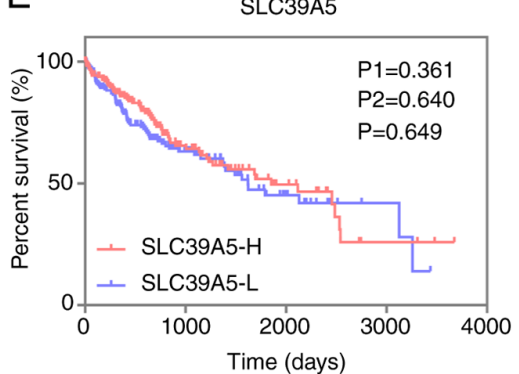

$\mathrm{H}$

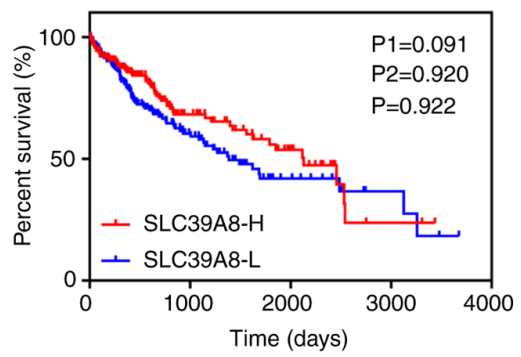

K

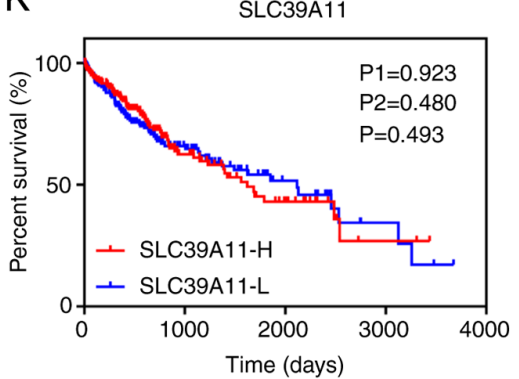

$\mathrm{N}$

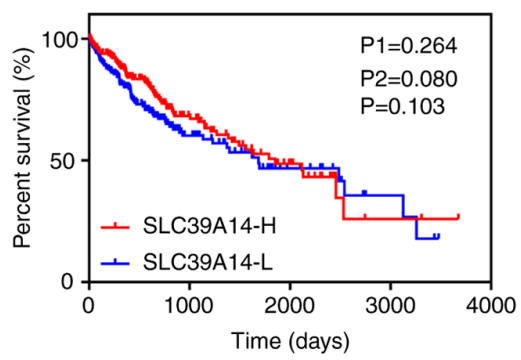

C

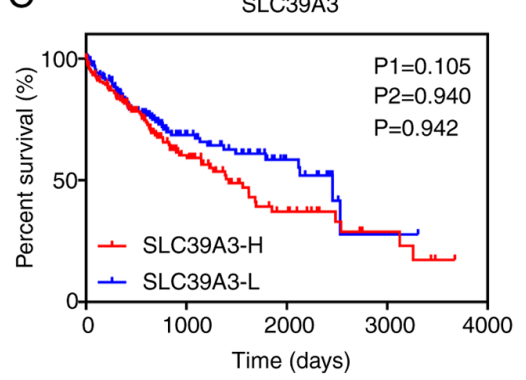

F

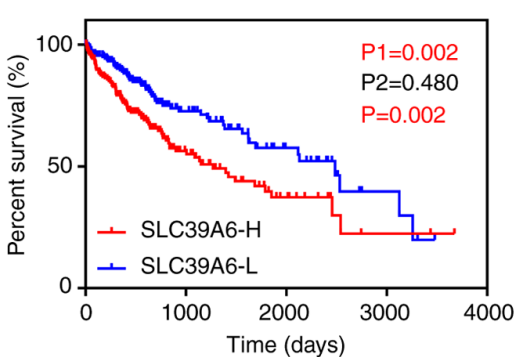

I

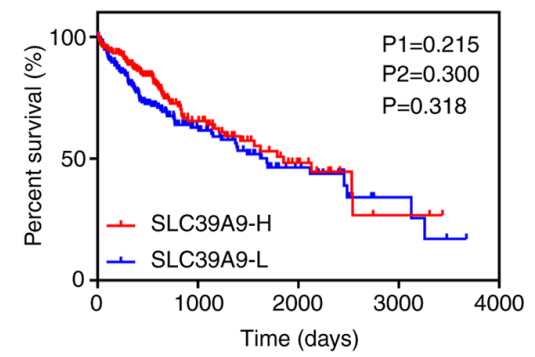

L

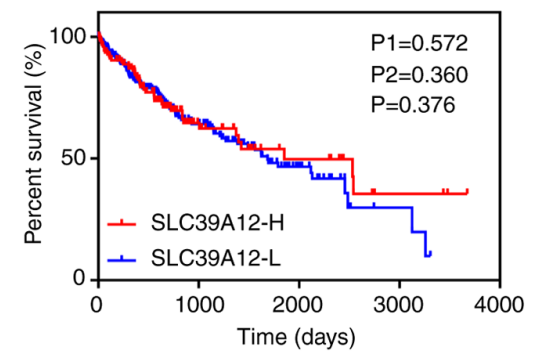

Figure 2. Association of SLC39A family genes with overall survival of patients with liver cancer based on data from the Gene Expression Profiling Interactive Analysis database. (A) SLC39A1, (B) SLC39A2, (C) SLC39A3, (D) SLC39A4, (E) SLC39A5, (F) SLC39A6, (G) SLC39A7, (H) SLC39A8, (I) SLC39A9, (J) SLC39A10, (K) SLC39A11, (L) SLC39A12, (M) SLC39A13 and (N) SLC39A14. P1 and P2 represent the P-value prior to and after curve crossing, respectively, and P represents the P-value for the whole graphs. P $<0.05$ was considered to indicate statistical significance. SLC, solute carrier; $\mathrm{H}$, high; L, low.

using the GEPIA database. As presented in Fig. 2A-N, positive associations were observed between high expression of several genes and a significantly unfavorable OS in patients with liver cancer, including SLC39A1, SLC39A6, SLC39A10 and SLC39A13. However, no positive associations were observed between high expression of genes and a significantly poorer 
Table I. Univariate and multivariate analyses of the influence of SLC39A mRNA levels and other factors on patient overall survival.

\begin{tabular}{|c|c|c|c|c|c|c|}
\hline \multirow[b]{2}{*}{ Variable } & \multicolumn{3}{|c|}{ Univariate analysis } & \multicolumn{3}{|c|}{ Multivariate analysis } \\
\hline & HR & $95 \% \mathrm{CI}$ & P-value & HR & $95 \% \mathrm{CI}$ & P-value \\
\hline SLC39A1 & 1.799 & $1.266-2.556$ & 0.001 & 1.462 & $1.011-2.112$ & 0.043 \\
\hline SLC39A2 & 1.072 & $0.760-1.514$ & 0.691 & & & \\
\hline SLC39A3 & 1.334 & $0.940-1.893$ & 0.107 & & & \\
\hline SLC39A4 & 1.039 & $0.735-1.468$ & 0.830 & & & \\
\hline SLC39A5 & 0.852 & $0.603-1.202$ & 0.361 & & & \\
\hline SLC39A6 & 1.736 & $1.222-2.465$ & 0.002 & 1.505 & $1.029-2.203$ & 0.035 \\
\hline SLC39A7 & 1.130 & $0.801-1.595$ & 0.487 & & & \\
\hline SLC39A8 & 0.742 & $0.525-1.050$ & 0.092 & & & \\
\hline SLC39A9 & 0.216 & $1.568-1.136$ & 0.216 & & & \\
\hline SLC39A10 & 1.801 & $1.265-2.565$ & 0.001 & 1.341 & $0.908-1.983$ & 0.141 \\
\hline SLC39A11 & 0.983 & $0.697-1.388$ & 0.923 & & & \\
\hline SLC39A12 & 0.899 & $0.621-1.301$ & 0.572 & & & \\
\hline SLC39A13 & 1.518 & $1.072-2.149$ & 0.019 & 1.429 & $1.000-2.041$ & 0.050 \\
\hline SLC39A14 & 0.822 & $0.582-1.161$ & 0.265 & & & \\
\hline Age & 1.186 & $0.836-1.683$ & 0.339 & & & \\
\hline Sex & 0.800 & $0.562-1.141$ & 0.218 & & & \\
\hline T stage & 1.682 & $1.403-2.017$ & $<0.001$ & 0.558 & $0.064-4.870$ & 0.597 \\
\hline $\mathrm{N}$ stage & 2.012 & $0.493-8.212$ & 0.330 & & & \\
\hline M stage & 1.055 & $1.274-12.906$ & 0.018 & 1.475 & $0.281-7.740$ & 0.646 \\
\hline TNM stage & 1.670 & $1.361-2.048$ & $<0.001$ & 0.245 & $0.032-1.845$ & 0.172 \\
\hline Grade & 1.114 & $0.881-1.408$ & 0.368 & & & \\
\hline Recurrence & 1.610 & $1.099-2.357$ & 0.014 & 0.640 & $0.392-1.043$ & 0.073 \\
\hline
\end{tabular}

Cutoff high, 50\%; cutoff low, 50\%. HR, hazard ratio; CI, confidence interval; TNM, Tumor Nodes Metastasis; SLC, solute carrier.

DFS (Fig. S1A-N). Furthermore, univariate and multivariate analyses of OS and DFS were performed to identify key genes of the SLC39A family in patients with liver cancer. The results suggested that SLC39A1, SLC39A6 or SLC39A13 overexpression was an influencing factor for poor prognosis of patients with liver cancer and may thus be a potential prognostic factor for liver cancer (Tables I and II). In this study, SLC39A6 was selected for follow-up experiments.

Association between the expression of SLC39A6 and the prognosis of patients with liver cancer. The Oncomine database and UCSC Xena browser were used to analyze the sequencing data of SLC39A6 in liver cancer. As presented in Fig. 3A-D, the mRNA expression levels of SLC39A6 were significantly higher in the tumor vs. normal tissues in the datasets by Mas et al (18), Chen et al (19) and Roessler et al (20). The expression levels of SLC39A6 in patients with different stages of liver cancer were also evaluated (Fig. 3E and F). The results revealed that increased expression of SLC39A6 mainly occurred in the late stages of liver cancer, while its expression level remained unaltered in patients with early-stage liver cancer.

Furthermore, survival curve analysis indicated that high expression of SLC39A6 was associated with markedly shorter OS and DFS of patients with different stages of liver cancer (Fig. 3G-L). These results suggested that the expression levels of SLC39A6 had a good diagnostic value for patients with liver cancer.

Protein expression and biological function of SLC39A6 in patients with liver cancer. To investigate the role of SLC39A6 in the progression of liver cancer, the mRNA and protein expression of SLC39A6 in T3 liver cancer tissues was analyzed using RT-qPCR, western blot analysis and IHC. The results revealed that SLC39A6 mRNA and protein expression in the tumor tissues was markedly higher than that in the corresponding non-cancerous tissues, indicating that SLC39A6 is an important target for liver cancer (Figs. 3M-O, 4A and S2A). GSEA was performed to evaluate the Kyoto Encyclopedia of Genes and Genomes and Gene Ontology gene sets in patients with liver cancer (Fig. 4B). The results revealed that the group with high expression of SLC39A6 was significantly enriched in gene sets associated with liver cancer, tumor adhesion and the tumor metastasis pathway. Thus, these results demonstrated that the expression of SLC39A6 was significantly upregulated in liver cancer tumor tissues and that it was associated with the tumor metastasis pathway.

Downregulation of SLC39A6 suppresses liver cancer cell growth, migration and invasion. To analyze the function of SLC39A6 in the biological behavior of liver cancer cells, HepG2 
Table II. Univariate and multivariate analyses of the influence of SLC39A mRNA levels and other factors on patient progressionfree interval.

\begin{tabular}{|c|c|c|c|c|c|c|}
\hline \multirow[b]{2}{*}{ Variable } & \multicolumn{3}{|c|}{ Univariate analysis } & \multicolumn{3}{|c|}{ Multivariate analysis } \\
\hline & HR & $95 \% \mathrm{CI}$ & P-value & HR & $95 \% \mathrm{CI}$ & P-value \\
\hline SLC39A1 & 1.096 & $0.819-1.466$ & 0.539 & & & \\
\hline SLC39A2 & 0.868 & $0.647-1.165$ & 0.347 & & & \\
\hline SLC39A3 & 0.911 & $0.680-1.219$ & 0.530 & & & \\
\hline SLC39A4 & 0.828 & $0.618-1.110$ & 0.207 & & & \\
\hline SLC39A5 & 0.932 & $0.697-1.247$ & 0.637 & & & \\
\hline SLC39A6 & 1.279 & $0.956-1.712$ & 0.098 & & & \\
\hline SLC39A7 & 0.941 & $0.703-1.260$ & 0.685 & & & \\
\hline SLC39A8 & 0.918 & $0.686-1.229$ & 0.567 & & & \\
\hline SLC39A9 & 1.020 & $0.762-1.366$ & 0.895 & & & \\
\hline SLC39A10 & 1.347 & $1.006-1.803$ & 0.046 & 1.295 & $0.907-1.850$ & 0.155 \\
\hline SLC39A11 & 0.859 & $0.641-1.151$ & 0.309 & & & \\
\hline SLC39A12 & 0.837 & $0.611-1.145$ & 0.264 & & & \\
\hline SLC39A13 & 1.083 & $0.809-1.449$ & 0.593 & & & \\
\hline SLC39A14 & 0.875 & $0.654-1.170$ & 0.368 & & & \\
\hline Age & 1.011 & $0.755-1.354$ & 0.941 & & & \\
\hline Sex & 0.979 & $0.718-1.334$ & 0.893 & & & \\
\hline T stage & 1.622 & $1.391-1.892$ & $<0.001$ & 1.284 & $0.588-2.805$ & 0.530 \\
\hline $\mathrm{N}$ stage & 1.379 & $0.340-5.586$ & 0.653 & & & \\
\hline M stage & 3.460 & $1.086-11.025$ & 0.036 & 1.094 & $0.315-3.795$ & 0.888 \\
\hline TNM stage & 1.660 & $1.397-1.973$ & $<0.001$ & 1.100 & $0.485-2.497$ & 0.820 \\
\hline Grade & 1.103 & $0.908-1.340$ & 0.322 & & & \\
\hline Recurrence & 23.799 & $12.902-43.900$ & $<0.001$ & 40.509 & $16.469-99.640$ & $<0.001$ \\
\hline
\end{tabular}

Cutoff high, 50\%; cutoff low, 50\%. HR, hazard ratio; CI, confidence interval; TNM, Tumor Nodes Metastasis; SLC, solute carrier.

and Hep3B cells were transfected with si-SLC39A6 to downregulate the expression of SLC39A6. HepG2 and Hep3B were the most commonly used cell lines to study liver cancer (30-34), so these cell lines were selected for the present study. In addition, the Cancer Cell Line Encyclopedia database (35-38) was checked and the results indicated that HepG2 and Hep3B were the liver cancer cell lines that expressed high SLC39A6. Thus, it was considered appropriate to select these two cell lines to study SLC39A6. As presented in Figs. 5A and S2B, the mRNA and protein expression of SLC39A6 was significantly decreased in the si-SLC39A6-transfected HepG2 and Hep3B cells. To determine whether SLC39A6 was essential for liver cancer cell proliferation, colony formation and CCK-8 assays were performed. In the colony formation assay, the colonies of the si-SLC39A6-transfected HepG2 and Hep3B cells were much smaller than those of the control cells (Figs. 5B and S2C). The results of the CCK- 8 assay also demonstrated that the growth of the si-SLC39A6-transfected HepG2 and Hep3B cells was significantly inhibited compared with that of the control cells (Fig. 5C).

Furthermore, the effects of SLC39A6 on the migration and invasion of liver cancer cells were investigated. As presented in Fig. 5D, the migratory and invasive ability of the si-SLC39A6-transfected HepG2 and Hep3B cells was significantly decreased compared with that of the control cells. These results revealed that knockdown of SLC39A6 inhibited the proliferation, migration and invasion of liver cancer cells.

Knockdown of SLC39A6 significantly suppresses liver cancer progression in vivo. In order to further verify the aforementioned observations, the role of SLC39A6 in the occurrence and development of liver cancer was investigated in vivo. As presented in Fig. S2D, the prognosis of patients with liver cancer was not significantly associated with sex. Furthermore, for the animal experiment, only female mice were available. HepG2 cells transfected with shRNA targeting SLC39A6 or the corresponding control vector were implanted subcutaneously into nude mice. The tumor size was strictly controlled to remain $<2,000 \mathrm{~mm}^{3}$ and the maximum percentage of body weight loss was $8.65 \%$ (Figs. 6A and S2E), fully complying with the ethical animal standards. The maximum tumor size observed was $1,648.70 \mathrm{~mm}^{3}$. The present results demonstrated that knockdown of SLC39A6 significantly reduced both the volume and weight of the tumors in vivo (Fig. 6A-C).

\section{Discussion}

Liver cancer is one of the most common malignant solid tumor types worldwide, with $>42,000$ new cases and 30,000 
A
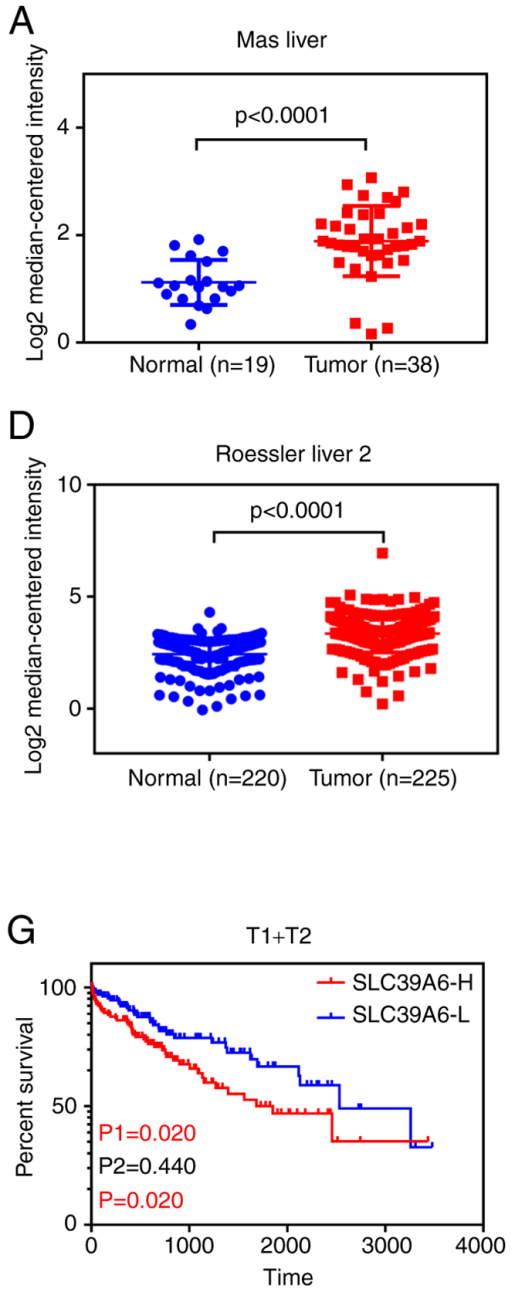

J

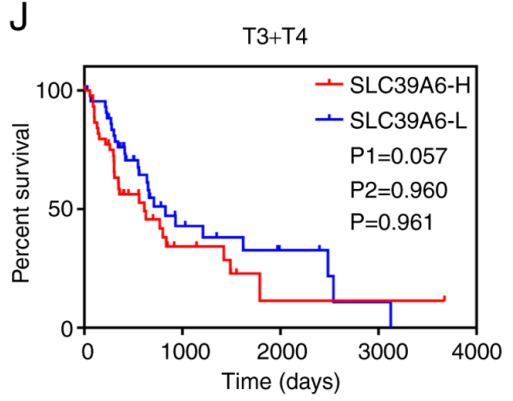

M

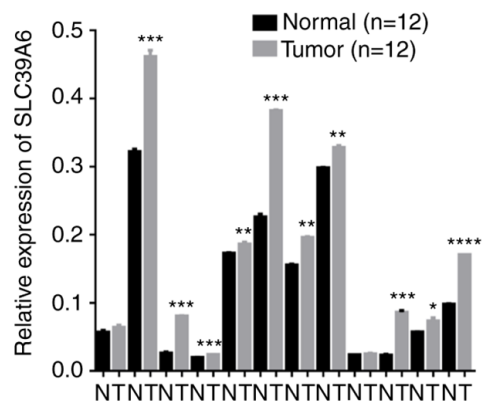

B

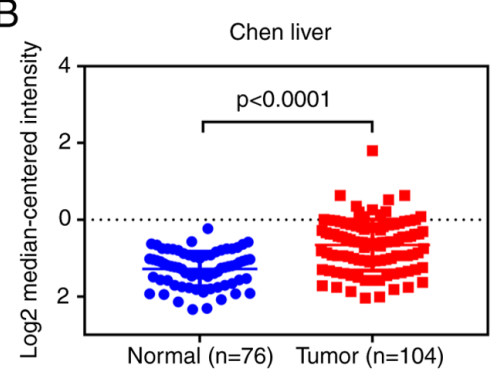

E

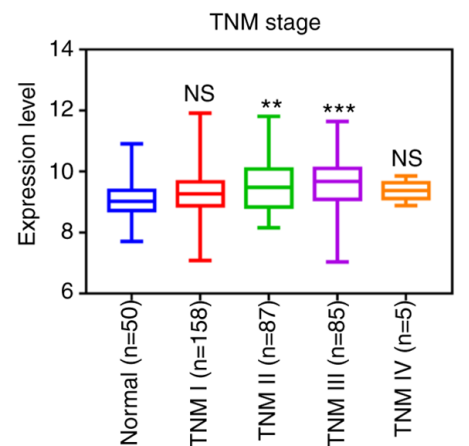

$\mathrm{H}$

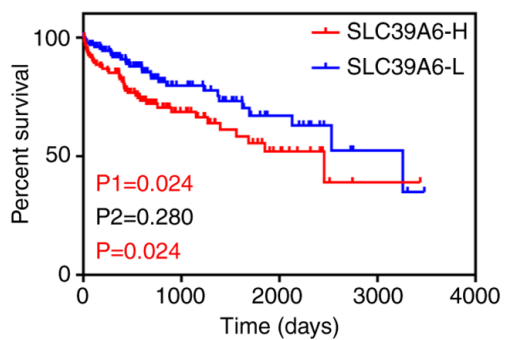

K

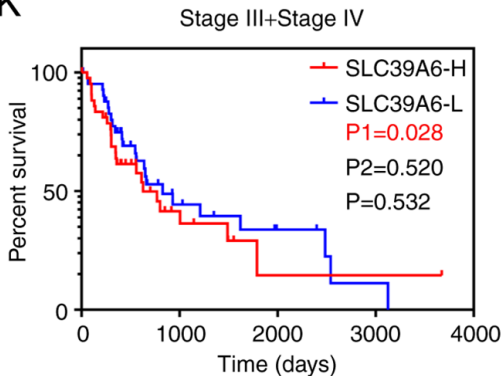

$N$

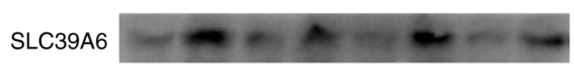

$\beta$-actin

SLC39A6

$\beta$-actin

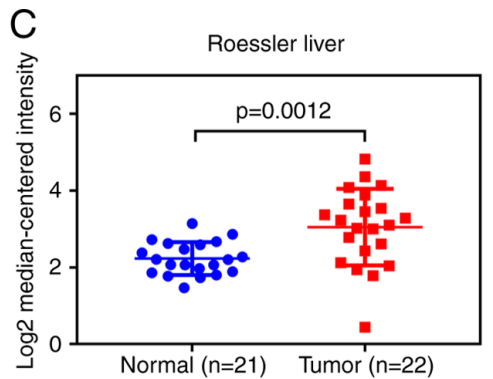

F
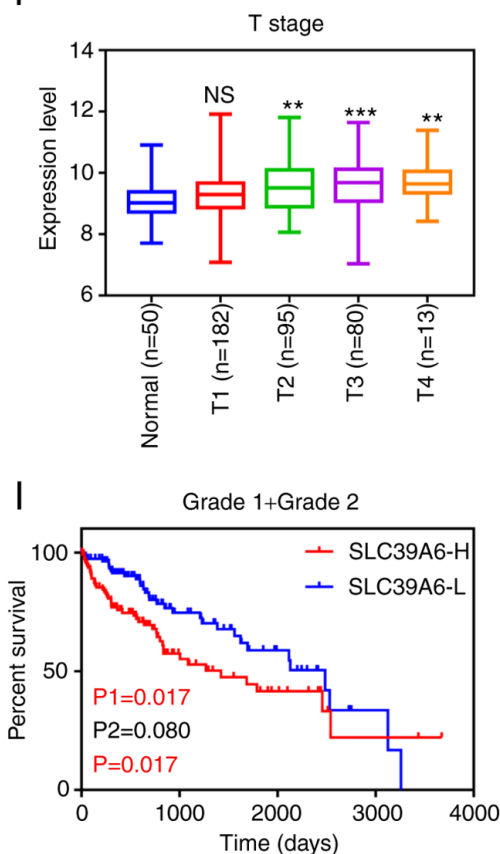

L

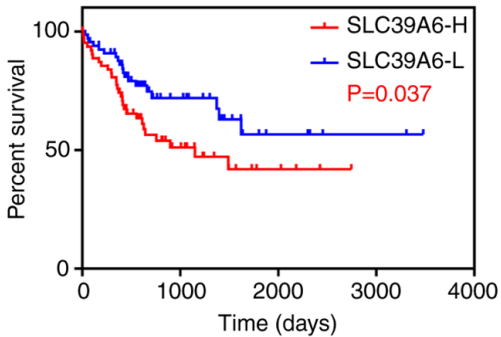

0

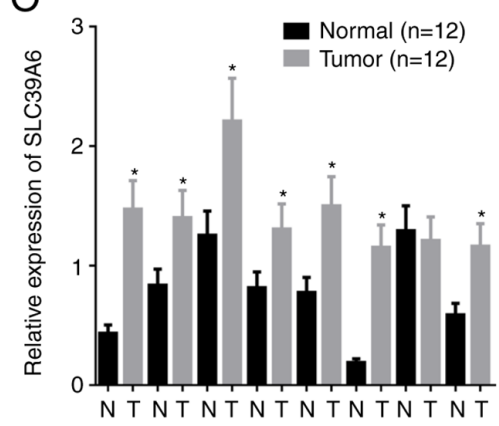

Figure 3. SLC39A6 expression is upregulated in patients with liver cancer and associated with poor prognosis. (A-D) Expression of SLC39A6 in patients with liver cancer based on the Oncomine database, including (A) Mas, (B) Chen and (C) Roessler Liver 1 and (D) Roessler Liver 2. (E and F) mRNA expression of SLC39A family genes in patients with liver cancer of different stages: (E) TNM stage and (F) T stage. (G-L) Association of SLC39A6 with overall survival of patients with liver cancer with different stages according to The Cancer Genome Atlas dataset. (G) T1 + T2; (H) stage I and II; (I) grade 1 and 2; (J) T3 + T4; (K) stage III and IV; (L) grade 3 and 4. P1 and P2 represent the P-value prior to and after curve crossing, respectively, and P represents the P-value for the whole graphs. (M) mRNA expression of SLC39A6 in liver cancer tissues and the corresponding noncancerous tissues. (N and O) Protein expression of SLC39A6 in liver cancer tissues and the corresponding noncancerous tissues: $(\mathrm{N})$ Representative western blot and $(\mathrm{O})$ quantified expression values. ${ }^{*} \mathrm{P}<0.05,{ }^{* *} \mathrm{P}<0.01$, ${ }^{* * *} \mathrm{P}<0.001$ vs. normal. SLC, solute carrier; H, high; L, low; NS, no significance; T, tumor; N, normal tissues. 
A

$A$
0
0
0
0
0
0
0
0
0
0
$\frac{1}{2}$
0
0
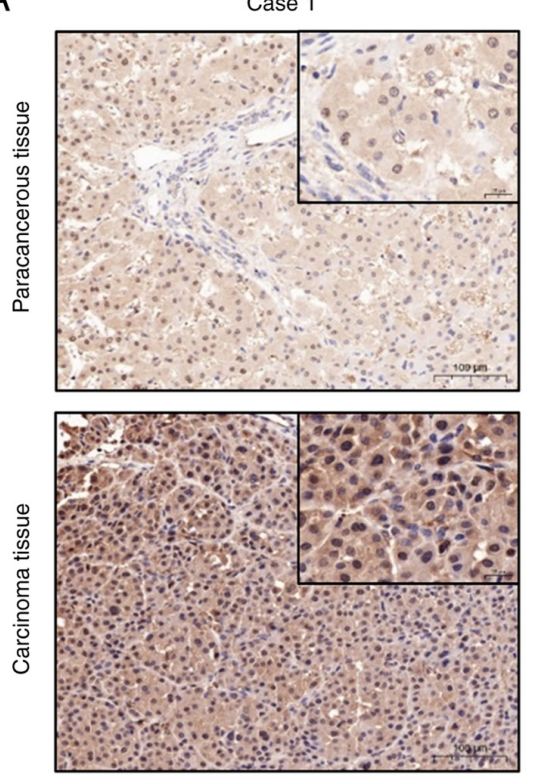

B

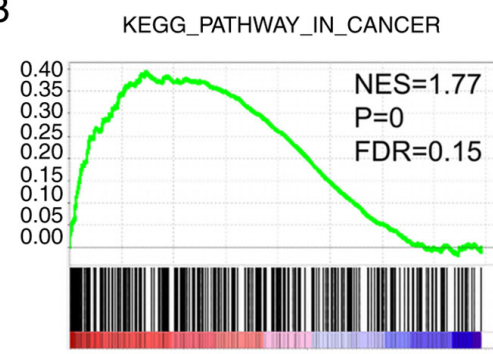

ALONSO_METASTASIS_EMT_UP

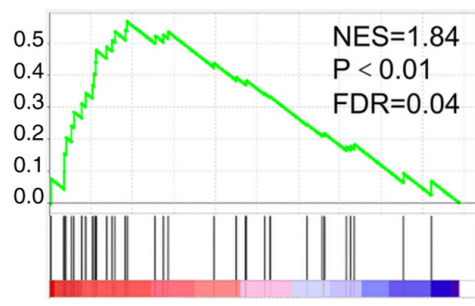

SEIDEN_ONCOGENESIS_BY_MET

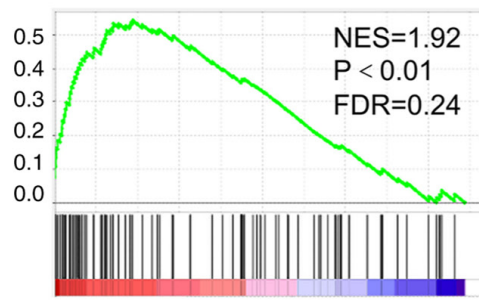

Case 2
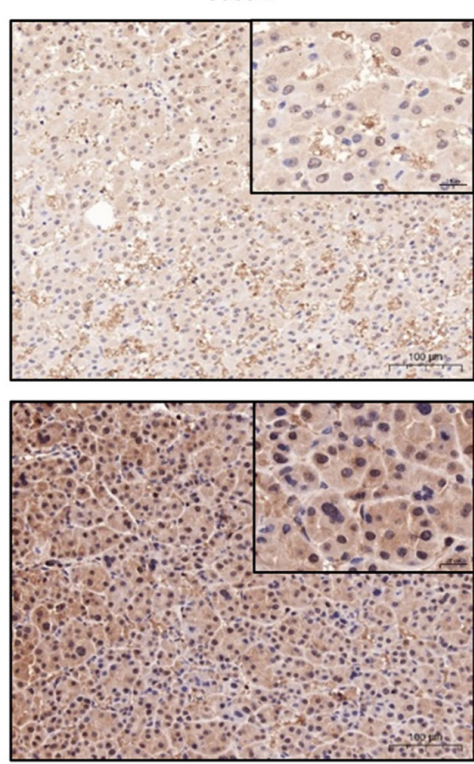

KEGG_WNT_SIGHALING_PATHWAY

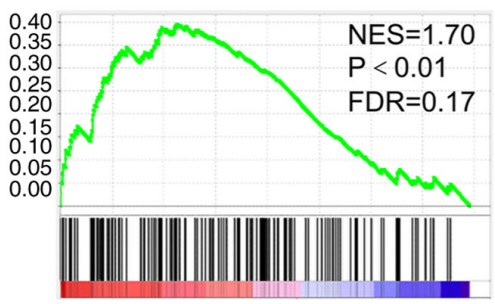

BIDUS_METASTASIS_UP

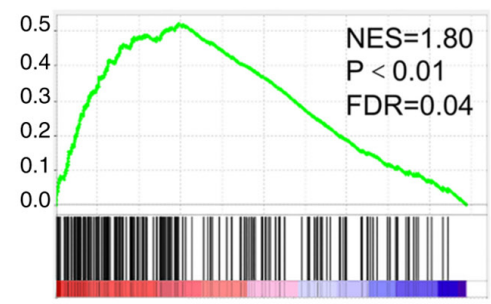

KAPOSI_LIVER_MET_UP

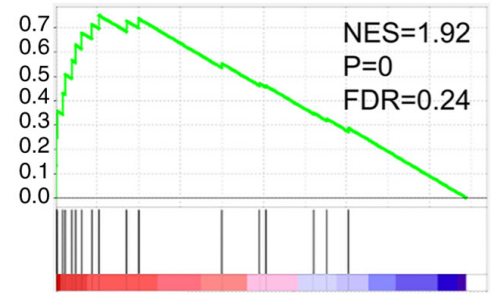

Case 3
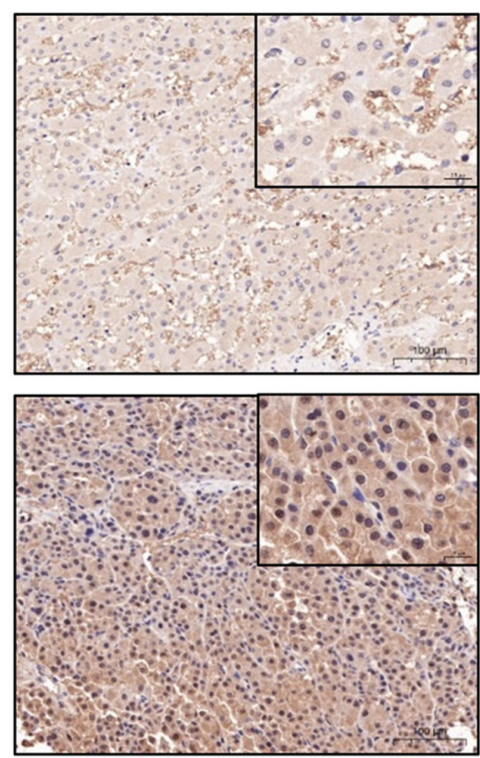

GO_CELL_ADHESION_MOLECULE -BINDING

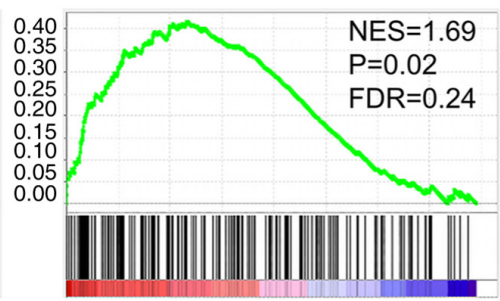

CROMER_TUMORIGENESIS_UP

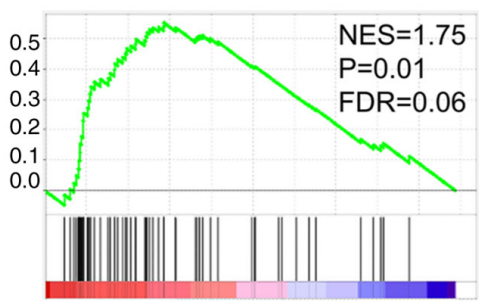

WHITFIELD_CELL_CYCLE_M_G1

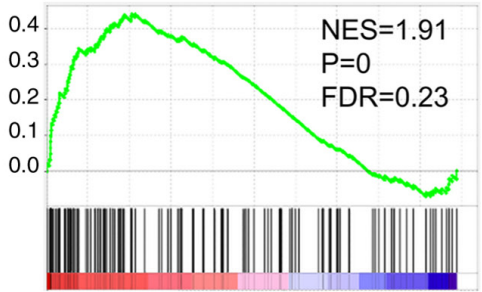

Figure 4. Expression and biological function of SLC39A6 in patients with liver cancer. (A) Typical immunohistochemical images of SLC39A6 expression in liver cancer tissues and the corresponding noncancerous tissues in three representative cases (magnification and scale bar, x100 and $100 \mu \mathrm{m}$, or x400 and $20 \mu \mathrm{m}$ in the magnified windows, respectively). (B) The liver cancer, tumor adhesion and tumor metastasis pathway were highly enriched in patients with liver cancer with SLC39A6 high expression according to gene set enrichment analysis of The Cancer Genome Atlas Liver Hepatocellular Carcinoma dataset. SLC, solute carrier; FDR, false discovery rate; KEGG, Kyoto Encyclopedia of Genes and Genomes; GO, Gene Ontology; EMT, epithelial-to-mesenchymal transition; NES, normalized enrichment score.

associated mortalities in 2020 (39). Among the primary cancers of the liver, hepatocellular carcinoma is the main histological subtype, accounting for $70-85 \%$ of the total cases (40). Although a variety of molecular changes have been detected over the past years (41-44), to the best of our knowledge, no sensitive and specific biomarkers and no accurate indicators are yet available for the early diagnosis or for predicting the prognosis of patients with liver cancer. Therefore, the early 


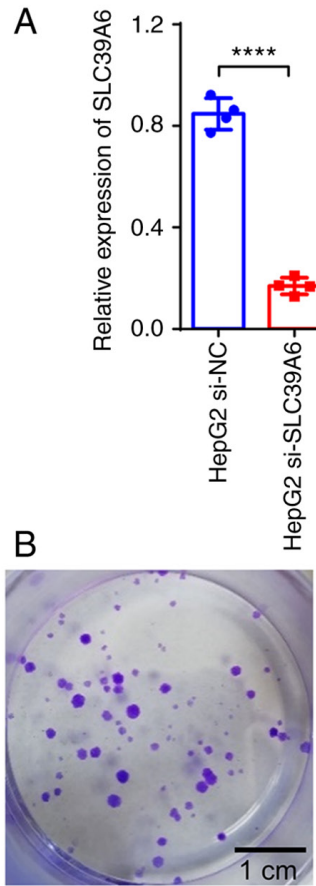

HepG2 si-NC
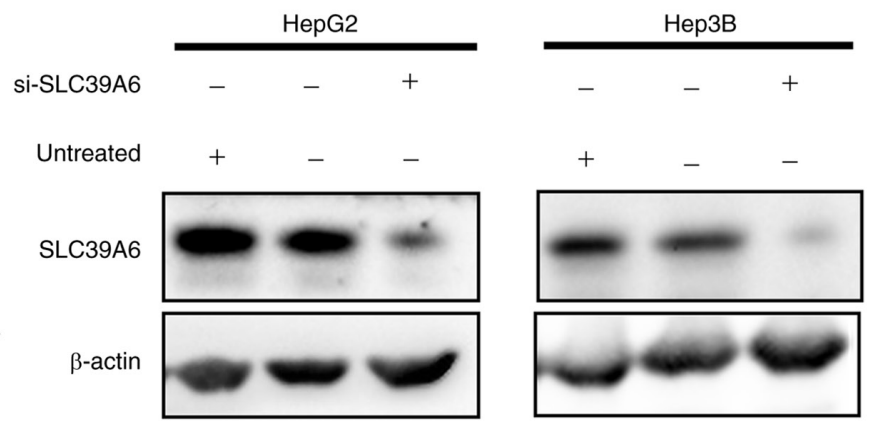

C

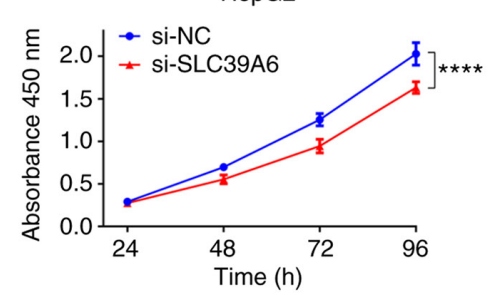

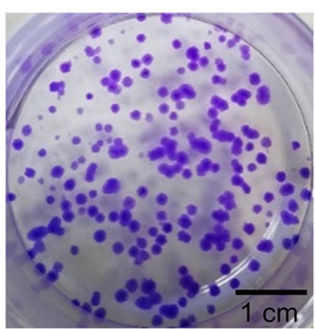

Hep3B si-NC

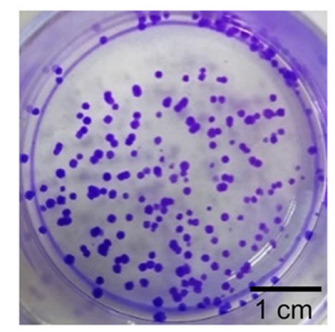

Hep3B si-SLC39A6

HepG2 si-SLC39A6

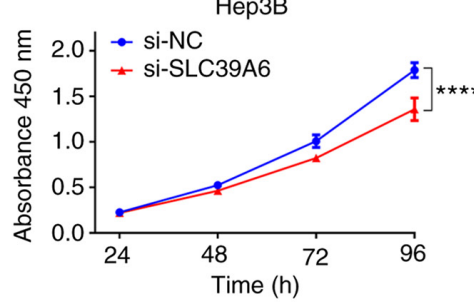

D
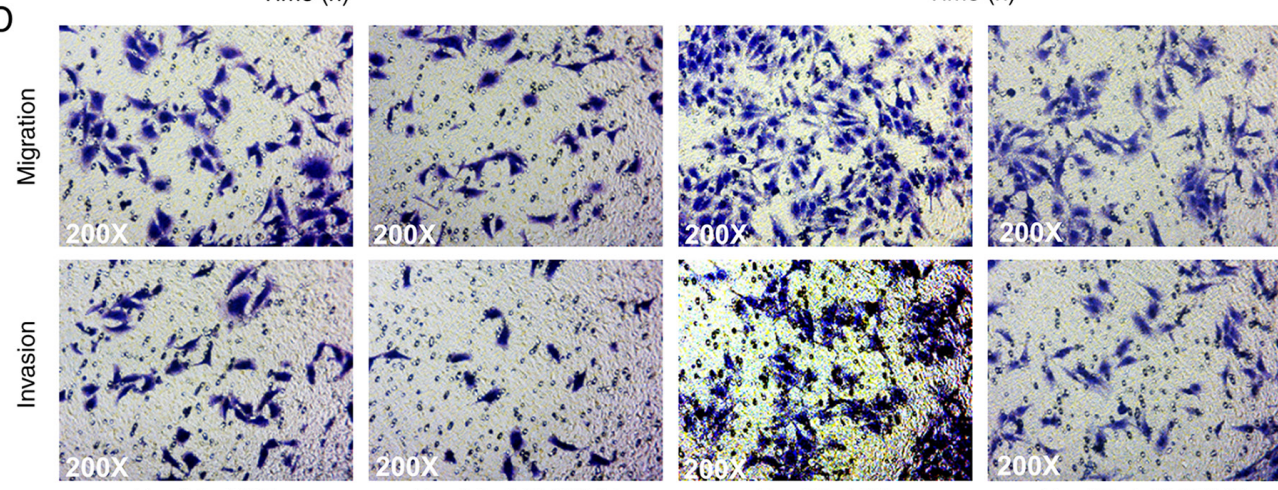
HepG2 si-SLC39A6

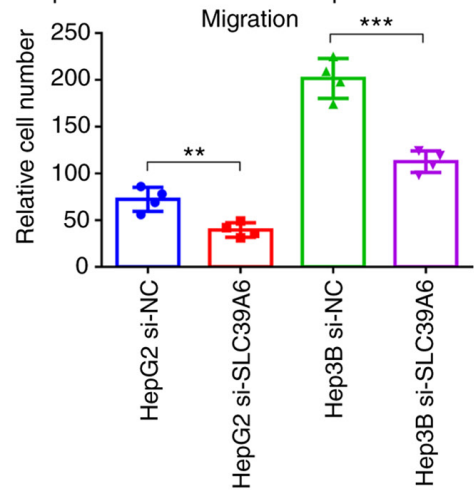

Hep3B si-NC
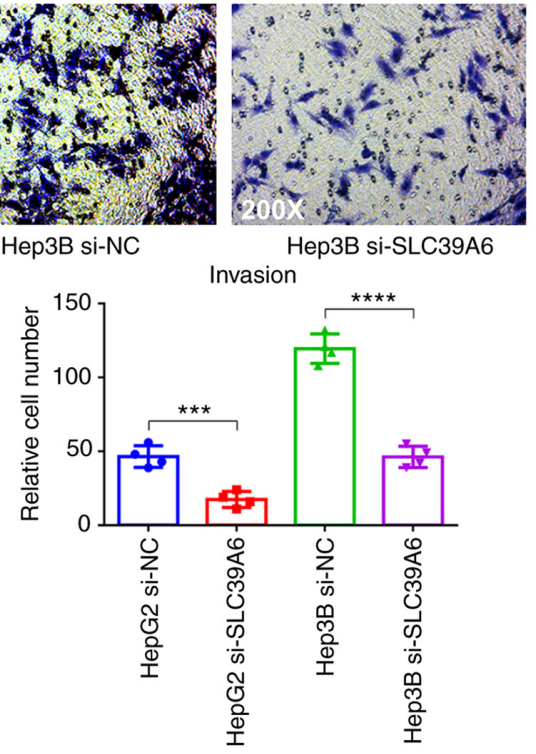

Hep3B si-SLC39A6

Figure 5. Knockdown of SLC39A6 inhibits liver cancer cell growth, migration and invasion in vitro. (A) Reverse transcription-quantitative PCR and western blot analyses of HepG2 and Hep3B cells transfected with si-NC and si-SLC39A6 were used to confirm knockdown. (B) Knockdown of SLC39A6 inhibited HepG2 and Hep3B cell growth in colony formation assays. Scale bar, $1 \mathrm{~cm}$. (C) Knockdown of SLC39A6 inhibited HepG2 and Hep3B cell growth in Cell Counting Kit-8 assays. (D) Images of migration and invasion assays of SLC39A6 knockdown-HepG2 and Hep3B cells. Magnification, x200. The data in each group are presented as the mean \pm standard deviation. ${ }^{* *} \mathrm{P}<0.01,{ }^{* * *} \mathrm{P}<0.001,{ }^{* * * *} \mathrm{P}<0.0001$. SLC, solute carrier; si-SLC39A6, small inhibitory RNA targeting SLC39A6; si-NC, negative control small inhibitory RNA. 

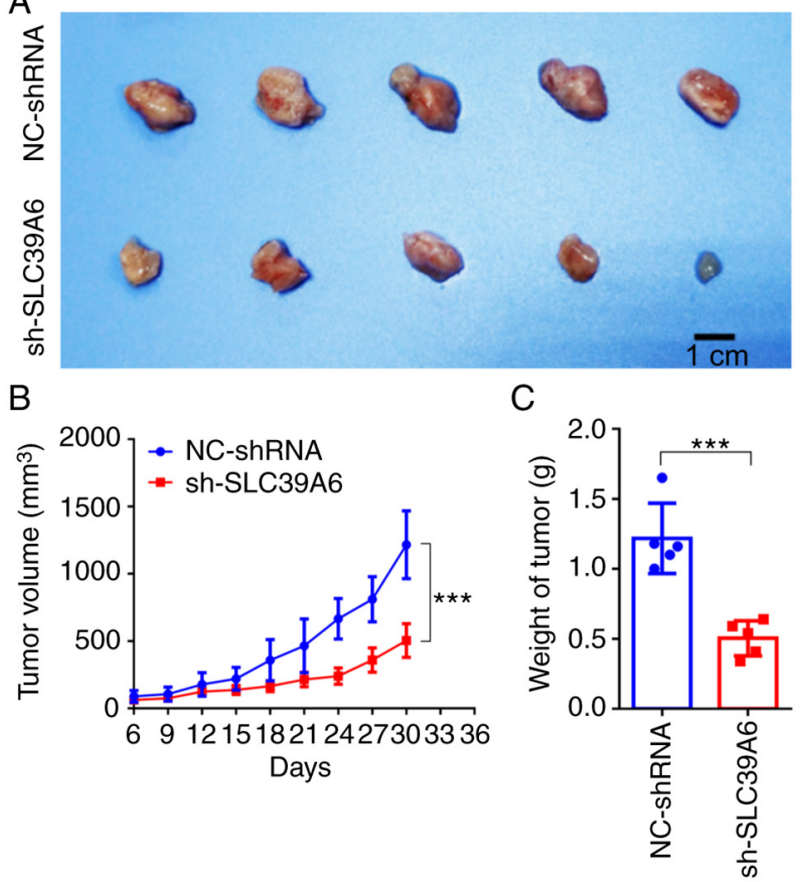

Figure 6. Knockdown of SLC39A6 significantly represses liver cancer growth in mice. (A) Images of tumors dissected from the mice. Scale bar, $1 \mathrm{~cm}$. (B) Curve of tumor volume $\left(\mathrm{mm}^{3}\right)$ over time. (C) Weight of tumors taken from the mice. Values are expressed as the mean \pm standard deviation for separate tumors of each group. ${ }^{* * * *} \mathrm{P}<0.001$ vs. NC-shRNA. SLC, solute carrier; sh-SLC39A6, short hairpin RNA targeting SLC39A6; NC, negative control.

detection of liver cancer is of utmost importance in order to improve the prognosis of patients with liver cancer.

Zinc usually has an important role in tumor events and low levels of zinc have been detected in serum and tumor tissues of patients with cancer $(45,46)$. SLC39A6 is a subfamily member of zinc transporters, which is involved in maintaining the intracellular homeostasis of zinc (47-49). Previous studies have demonstrated that SLC39A6 is overexpressed in breast $(50,51)$, pancreatic and cervical cancer $(52,53)$, as well as in esophageal squamous cell carcinoma $(54,55)$. In liver cancer, a previous study indicated that miR-192 was a prognostic indicator, reducing liver cancer metastasis through the SLC39A6/SNAIL pathway (56). However, whether SLC39A6 expression is an independent prognostic factor for patients with liver cancer warrants further exploration.

In the present study, the mRNA expression of SLC39A family genes in liver cancer tissues and their association with OS of patients with liver cancer was analyzed. The results revealed that the expression levels of SLC39A1, SLC39A3, SLC39A4, SLC39A6, SLC39A7, SLC39A10 and SLC39A13 were significantly higher in the tumor compared with healthy tissues, while SLC39A5, SLC39A9, SLC39A11 and SLC39A14 were expressed at higher levels in healthy tissues. The results demonstrated that high expression of SLC39A1, SLC39A6, SLC39A10 and SLC39A12 was associated with unfavorable OS of patients with liver cancer. The expression of SLC39A members was associated with the prognosis of specific patients with liver cancer by subgroup analysis. In addition, Cox regression analysis confirmed that SLC39A6 was a key gene influencing the survival of patients with liver cancer. All of these results indicated that SLC39A6 may be a biomarker for the early detection and prognosis of liver cancer.

As metastasis is the main cause of liver cancer-related mortality, the identification of new genes involved in this process is crucial in order to elucidate the molecular mechanism of liver cancer metastasis $(57,58)$. The present study observed the upregulation of SLC39A6 expression in liver cancer tumor tissues and cell lines. GSEA also revealed that SLC39A6 was associated with liver cancer tumor proliferation and metastasis.

In recent years, studies have indicated that SLC39A6 has an important role in tumor progression, metastasis and invasion. With regard to breast cancer, the expression of SLC39A6 has been indicated to be significantly increased compared with that in normal breast tissue and the expression of the adhesion protein, E-cadherin, has been reported to be significantly decreased following overexpression of SLC39A6. It was thus revealed that SLC39A6 may promote epithelial-mesenchymal transition (EMT) in breast cancer (59). Furthermore, it was reported that SLC39A6 is activated by STAT3 in breast tumor cells, triggering the influx of zinc ions and promoting Snail to remain in the nucleus as an E-cadherin transcription inhibitor, thus promoting the migration process. Therefore, SLC39A6 has been proposed as a novel target for breast cancer (60). In addition, the expression of SLC39A6 has been indicated to be markedly higher in pancreatic tumors than in normal pancreatic tissues. Furthermore, the proliferative and migratory ability of pancreatic cancer cells has been indicated to decrease significantly following SLC39A6 knockdown (61). Another study demonstrated that SLC39A6 enhanced the invasive phenotype by inducing the EMT of pancreatic cancer cells (52). With regard to non-small cell lung cancer, knockdown of SLC39A6 has been reported to significantly inhibit the proliferation, migration and invasion of lung cancer cells and to induce cell cycle arrest in G1 phase (62). These results indicate that SLC39A6 promotes the development of multiple tumor types, which is consistent with the findings of the present study on liver cancer.

In the present study, in order to verify whether SLC39A6 promotes the proliferation, migration and invasion of liver cancer cells, the expression of SLC39A6 in HepG2 and Hep3B cells was knocked down. The results of a CCK- 8 assay indicated that knockdown of SLC39A6 significantly decreased the viability and proliferation of HepG2 and Hep3B cells. Furthermore, in the Transwell assays, it was observed that knockdown of SLC39A6 significantly reduced the number of migrating and invading HepG 2 and Hep3B cells. These results demonstrated that SLC39A6 significantly regulated the proliferation, migration and invasion of liver cancer cells, thus regulating the malignant progression of liver cancer. Of note, in vivo, it was demonstrated that the knockdown of SLC39A6 significantly inhibited the progression of liver cancer.

In conclusion, in the present study, SLC39A6 was identified as a key gene of the SLC39A family in liver cancer. The results demonstrated that SLC39A6 was upregulated in liver cancer, indicating that it may be used as a potential biomarker for the diagnosis of liver cancer. Furthermore, knockdown of SLC39A6 expression significantly reduced the proliferation, migration and invasion of HepG2 and Hep3B cells in vitro 
and also significantly suppressed liver cancer growth in vivo. Collectively, the results of the present study demonstrated that SLC39A6 may have a crucial tumor-promoting role in liver cancer and may exhibit the potential for use as a therapeutic target for liver cancer.

\section{Acknowledgements}

Not applicable.

\section{Funding}

This work was supported by grants from the National Nature Science Foundation of China (grant no. 81760137) and the Nature Science Foundation of Jiangxi Province (grant no. 20202BAB206016).

\section{Availability of data and materials}

The datasets used and/or analyzed during the current study are available from the corresponding author on reasonable request.

\section{Authors' contributions}

ZW participated in the conception and design of the study. ZW and XW performed the experiments, data analysis and interpretation. ZW provided the resources. ZW and XW wrote the manuscript. ZW and XW confirm the authenticity of all the raw data. All authors read and approved the final manuscript.

\section{Ethics approval and consent to participate}

The present study was approved by the Human Research Ethics Committee of Nanchang University (Nanchang, China; approval no. 2021-027). All of the patients were fully informed of the study procedures orally and signed an informed consent form.

\section{Patient consent for publication}

Not applicable.

\section{Competing interests}

The authors declare that they have no competing interests.

\section{References}

1. Villanueva A: Hepatocellular carcinoma. N Engl J Med 380: 1450-1462, 2019.

2. Jemal A, Ward EM, Johnson CJ, Cronin KA, Ma J, Ryerson B, Mariotto A, Lake AJ, Wilson R, Sherman RL, et al: Annual report to the nation on the status of cancer, 1975-2014, featuring survival. J Natl Cancer Inst 109: djx030, 2017.

3. Zheng R, Qu C, Zhang S, Zeng H, Sun K, Gu X, Xia C, Yang Z, Li H, Wei W, et al: Liver cancer incidence and mortality in China: Temporal trends and projections to 2030. Chin J Cancer Res 30: 571-579, 2018

4. Sia D, Villanueva A, Friedman SL and Llovet JM: Liver cancer cell of origin, molecular class, and effects on patient prognosis. Gastroenterology 152: 745-761, 2017.

5. Idilman R, De Maria N, Colantoni A and Van Thiel DH: Pathogenesis of hepatitis $\mathrm{B}$ and $\mathrm{C}$-induced hepatocellular carcinoma. J Viral Hepat 5: 285-299, 1998.
6. Kanwal F, Kramer JR, Duan Z, Yu X, White D and El-Serag HB: Trends in the burden of nonalcoholic fatty liver disease in a united states cohort of veterans. Clin Gastroenterol Hepatol 14: 301-8.e1-e2, 2016.

7. Morgan TR, Mandayam S and Jamal MM: Alcohol and hepatocellular carcinoma. Gastroenterology 127 (5 Suppl 1): S87-S96, 2004.

8. Forner A, Reig M and Bruix J: Hepatocellular carcinoma. Lancet 391: 1301-1314, 2018.

9. Pan Z, Choi S, Ouadid-Ahidouch H, Yang JM, Beattie JH and Korichneva I: Zinc transporters and dysregulated channels in cancers. Front Biosci (Landmark Ed) 22: 623-643, 2017.

10. Ho E and Ames BN: Low intracellular zinc induces oxidative DNA damage, disrupts p53, NFkappa B, and AP1 DNA binding, and affects DNA repair in a rat glioma cell line. Proc Natl Acad Sci USA 99: 16770-16775, 2002.

11. Vallee BL and Falchuk KH: The biochemical basis of zinc physiology. Physiol Rev 73: 79-118, 1993.

12. Andreini C, Banci L, Bertini I and Rosato A: Counting the zinc-proteins encoded in the human genome. J Proteome Res 5: 196-201, 2006

13. Huang L and Tepaamorndech S: The SLC30 family of zinc transporters-a review of current understanding of their biological and pathophysiological roles. Mol Aspects Med 34: 548-560, 2013.

14. Jeong $\mathrm{J}$ and Eide DJ: The SLC 39 family of zinc transporters. Mol Aspects Med 34: 612-619, 2013.

15. Costello LC and Franklin RB: The clinical relevance of the metabolism of prostate cancer; zinc and tumor suppression: Connecting the dots. Mol Cancer 5: 17, 2006.

16. Liu L, Hou Y, Hu J, Zhou L, Chen K, Yang X and Song Z: SLC39A8/Zinc suppresses the progression of clear cell renal cell carcinoma. Front Oncol 11: 651921, 2021.

17. Liu L, Yang J and Wang C: Analysis of the prognostic significance of solute carrier (SLC) family 39 genes in breast cancer. Biosci Rep 40: BSR20200764, 2020.

18. Mas VR, Maluf DG, Archer KJ, Yanek K, Kong X, Kulik L, Freise CE, Olthoff KM, Ghobrial RM, McIver P and Fisher R: Genes involved in viral carcinogenesis and tumor initiation in hepatitis $\mathrm{C}$ virus-induced hepatocellular carcinoma. Mol Med 15: 85-94, 2009.

19. Chen X, Cheung ST, So S, Fan ST, Barry C, Higgins J, Lai KM, Ji J, Dudoit S, Ng IO, et al: Gene expression patterns in human liver cancers. Mol Biol Cell 13: 1929-1939, 2002.

20. Roessler S, Jia HL, Budhu A, Forgues M, Ye QH, Lee JS, Thorgeirsson SS, Sun Z, Tang ZY, Qin LX and Wang XW: A unique metastasis gene signature enables prediction of tumor relapse in early-stage hepatocellular carcinoma patients. Cancer Res 70: 10202-10212, 2010.

21. Chen P, Yao Y, Yang N, Gong L, Kong Y and Wu A: Circular RNA circCTNNA1 promotes colorectal cancer progression by sponging miR-149-5p and regulating FOXM1 expression. Cell Death Dis 11: 557, 2020.

22. Livak KJ and Schmittgen TD: Analysis of relative gene expression data using real-time quantitative PCR and the 2(-Delta Delta C(T)) method. Methods 25: 402-408, 2001.

23. Workman P, Aboagye EO, Balkwill F, Balmain A, Bruder G, Chaplin DJ, Double JA, Everitt J, Farningham DA, Glennie MJ, et al: Guidelines for the welfare and use of animals in cancer research. Br J Cancer 102: 1555-1577, 2010.

24. Kang JC, Sun W, Khare P, Karimi M, Wang X, Shen Y, Ober RJ and Ward ES: Engineering a HER2-specific antibody-drug conjugate to increase lysosomal delivery and therapeutic efficacy. Nat Biotechnol 37: 523-526, 2019.

25. Xiao H, Guo Y, Li B, Li X, Wang Y, Han S, Cheng D and Shuai X: M2-like tumor-associated macrophage-targeted codelivery of STAT6 inhibitor and IKK $\beta$ siRNA induces M2-to-M1 repolarization for cancer immunotherapy with low immune side effects. ACS Cent Sci 6: 1208-1222, 2020.

26. Wang X, Wilhelm J, Li W, Li S, Wang Z, Huang G, Wang J, Tang H, Khorsandi S, Sun Z, et al: Polycarbonate-based ultra-pH sensitive nanoparticles improve therapeutic window. Nat Commun 11: 5828, 2020.

27. Chongsathidkiet P, Jackson C, Koyama S, Loebel F, Cui X, Farber SH, Woroniecka K, Elsamadicy AA, Dechant CA, Kemeny HR, et al: Sequestration of $\mathrm{T}$ cells in bone marrow in the setting of glioblastoma and other intracranial tumors. Nat Med 24: 1459-1468, 2018.

28. Xu YL, Ding CL, Qian CL, Qi ZT and Wang W: Retinoid acid induced 16 deficiency aggravates colitis and colitis-associated tumorigenesis in mice. Cell Death Dis 10: 958, 2019. 
29. Qiu P and Sheng J: A two-stage procedure for comparing hazard rate functions. J R Statist Soc B 70: 191-208, 2008.

30. Moh MC, Lee LH, Yang X and Shen S: HEPN1, a novel gene that is frequently down-regulated in hepatocellular carcinoma, suppresses cell growth and induces apoptosis in HepG2 cells. J Hepatol 39: 580-586, 2003.

31. Notas G, Kolios G, Mastrodimou N, Kampa M, Vasilaki A, Xidakis C, Castanas E, Thermos $\mathrm{K}$ and Kouroumalis E: Cortistatin production by HepG2 human hepatocellular carcinoma cell line and distribution of somatostatin receptors. J Hepatol 40: 792-798, 2004.

32. Wu JM, Xu Y, Skill NJ, Sheng H, Zhao Z, Yu M, Saxena R and Maluccio MA: Autotaxin expression and its connection with the TNF-alpha-NF-kappaB axis in human hepatocellular carcinoma. Mol Cancer 9: 71, 2010 .

33. Chang Y, Yan W, He X, Zhang L, Li C, Huang H, Nace G, Geller DA, Lin J and Tsung A: miR-375 inhibits autophagy and reduces viability of hepatocellular carcinoma cells under hypoxic conditions. Gastroenterology 143: 177-187.e8, 2012.

34. Prieto-DomínguezN,OrdóñezR,Fernández A,Méndez-Blanco C Baulies A, Garcia-Ruiz C, Fernández-Checa JC, Mauriz JL and González-Gallego J: Melatonin-induced increase in sensitivity of human hepatocellular carcinoma cells to sorafenib is associated with reactive oxygen species production and mitophagy. J Pineal Res 61: 396-407, 2016.

35. Jaffe JD, Wang Y, Chan HM, Zhang J, Huether R, Kryukov GV, Bhang HE, Taylor JE, Hu M, Englund NP, et al: Global chromatin profiling reveals NSD2 mutations in pediatric acute lymphoblastic leukemia. Nat Genet 45: 1386-1391, 2013.

36. Ghandi M, Huang FW, Jané-Valbuena J, Kryukov GV, Lo CC, McDonald ER III, Barretina J, Gelfand ET, Bielski CM, $\mathrm{Li} \mathrm{H}$, et al: Next-generation characterization of the cancer cell line encyclopedia. Nature 569: 503-508, 2019.

37. Li H, Ning S, Ghandi M, Kryukov GV, Gopal S, Deik A, Souza A, Pierce K, Keskula P, Hernandez D, et al: The landscape of cancer cell line metabolism. Nat Med 25: 850-860, 2019.

38. Nusinow DP, Szpyt J, Ghandi M, Rose CM, McDonald ER III, Kalocsay M, Jané-Valbuena J, Gelfand E, Schweppe DK, Jedrychowski M, et al: Quantitative proteomics of the cancer cell line encyclopedia. Cell 180: 387-402.e16, 2020.

39. Siegel RL, Miller KD and Jemal A: Cancer statistics, 2020. CA Cancer J Clin 70: 7-30, 2020.

40. Perz JF, Armstrong GL, Farrington LA, Hutin YJF and Bell BP: The contributions of hepatitis $B$ virus and hepatitis $C$ virus infections to cirrhosis and primary liver cancer worldwide. J Hepatol 45: 529-538, 2006.

41. Hartke J, Johnson M and Ghabril M: The diagnosis and treatment of hepatocellular carcinoma. Semin Diagn Pathol 34: 153-159, 2017.

42. Ayuso C, Rimola J, Vilana R, Burrel M, Darnell A, García-Criado Á, Bianchi L, Belmonte E, Caparroz C, Barrufet M, et al: Diagnosis and staging of hepatocellular carcinoma (HCC): Current guidelines. Eur J Radiol 101: 72-81, 2018.

43. Piñero F, Dirchwolf M and Pessôa MG: Biomarkers in hepatocellular carcinoma: Diagnosis, prognosis and treatment response assessment. Cells 9: 1370, 2020.

44. Chowdhury MMH, Salazar CJJ and Nurunnabi M: Recent advances in bionanomaterials for liver cancer diagnosis and treatment. Biomater Sci 9: 4821-4842, 2021.

45. Fukada T, Yamasaki S, Nishida K, Murakami M and Hirano T: Zinc homeostasis and signaling in health and diseases: Zinc signaling. J Biol Inorg Chem 16: 1123-1134, 2011.

46. Kolenko V, Teper E, Kutikov A and Uzzo R: Zinc and zinc transporters in prostate carcinogenesis. Nat Rev Urol 10: 219-226, 2013.
47. Bafaro E, Liu Y, Xu Y and Dempski RE: The emerging role of zinc transporters in cellular homeostasis and cancer. Signal Transduct Target Ther 2: 17029, 2017.

48. Eide DJ: The SLC39 family of metal ion transporters. Pflugers Arch 447: 796-800, 2004

49. Schweigel-Röntgen M: The families of zinc (SLC30 and SLC39) and copper (SLC31) transporters. Curr Top Membr 73: 321-355, 2014.

50. Grattan BJ and Freake HC: Zinc and cancer: Implications for LIV-1 in breast cancer. Nutrients 4: 648-675, 2012.

51. Taylor KM, Morgan HE, Smart K, Zahari NM, Pumford S, Ellis IO, Robertson JF and Nicholson RI: The emerging role of the LIV-1 subfamily of zinc transporters in breast cancer. Mol Med 13: 396-406, 2007.

52. Unno J, Satoh K, Hirota M, Kanno A, Hamada S, Ito H, Masamune A, Tsukamoto N, Motoi F, Egawa S, et al: LIV-1 enhances the aggressive phenotype through the induction of epithelial to mesenchymal transition in human pancreatic carcinoma cells. Int J Oncol 35: 813-821, 2009.

53. Zhao L, Chen W, Taylor KM, Cai B and Li X: LIV-1 suppression inhibits HeLa cell invasion by targeting ERK1/2-Snail/Slug pathway. Biochem Biophys Res Commun 363: 82-88, 2007.

54. Wu C, Li D, Jia W, Hu Z, Zhou Y, Yu D, Tong T, Wang M, Lin D, Qiao Y, et al: Genome-wide association study identifies common variants in SLC39A6 associated with length of survival in esophageal squamous-cell carcinoma. Nat Genet 45: 632-638, 2013.

55. Cui XB, Shen YY, Jin TT, Li S, Li TT, Zhang SM, Peng H, Liu CX, Li SG, Yang L, et al: SLC39A6: A potential target for diagnosis and therapy of esophageal carcinoma. J Transl Med 13: $321,2015$.

56. Lian J, Jing Y, Dong Q, Huan L, Chen D, Bao C, Wang Q, Zhao F, Li J, Yao M, et al: miR-192, a prognostic indicator, targets the SLC39A6/SNAIL pathway to reduce tumor metastasis in human hepatocellular carcinoma. Oncotarget 7: 2672-2683, 2016.

57. Ge Y, Mu W, Ba Q, Li J, Jiang Y, Xia Q and Wang H: Hepatocellular carcinoma-derived exosomes in organotropic metastasis, recurrence and early diagnosis application. Cancer Lett 477: 41-48, 2020

58. Subbotin VM: Privileged portal metastasis of hepatocellular carcinoma in light of the coevolution of a visceral portal system and liver in the chordate lineage: A search for therapeutic targets. Drug Discov Today 23: 548-564, 2018.

59. Chandler P, Kochupurakkal BS, Alam S, Richardson AL, Soybel DI and Kelleher SL: Subtype-specific accumulation of intracellular zinc pools is associated with the malignant phenotype in breast cancer. Mol Cancer 15: 2, 2016.

60. Hogstrand C, Kille P, Ackland ML, Hiscox S and Taylor KM: A mechanism for epithelial-mesenchymal transition and anoikis resistance in breast cancer triggered by zinc channel ZIP6 and STAT3 (signal transducer and activator of transcription 3). Biochem J 455: 229-237, 2013.

61. Unno J, Masamune A, Hamada S and Shimosegawa T: The zinc transporter LIV-1 is a novel regulator of stemness in pancreatic cancer cells. Scand J Gastroenterol 49: 215-221, 2014.

62. Wan X, Kong Z, Chu K, Yi C, Hu J, Qin R, Zhao C, Fu F, Wu H, Li Y and Huang Y: Co-expression analysis revealed PTCH1-3'UTR promoted cell migration and invasion by activating miR-101-3p/SLC39A6 axis in non-small cell lung cancer: Implicating the novel function of PTCH1. Oncotarget 9: 4798-4813, 2018.

This work is licensed under a Creative Commons Attribution-NonCommercial-NoDerivatives 4.0 International (CC BY-NC-ND 4.0) License. 